\title{
Two Brief Thoughts on Technical Assistance (put simply and with some provocative exaggeration)
}

\author{
by Ron Dore ${ }^{1}$
}

1. Never send a technical assistant where a machine will do

Many people have, no doubt, shared the frustrating experience of using a telephone in an African capital city. One decent automatic telephone exchange which gave back to African civil servants that one-fifth of their time and energy which they now spend on frustrating battles with telephones and telephone operators would do more to increase their efficiency than 20 courses ir public administration.

The need for efficient printing presses, supplies of newsprint, various kinds of telecommunications, is overwhelming.

By all means send material technologists to service the machines - telephone engineers, master printers, etc. But put yoir money on these rather than on social technologists.

2. When selecting technical assistants for social technology jobs, knowledge of the local culture, intelligence and the right attitudes are of much greater importance than formal qualifications and even than breadth of experience

The more the job involves attempts to alter behaviour, values, attitudes - as par excellence in the field of education - the more important this is. Years spent in the country is wholly inadequate as a measure of local knowledge. Fluency in local language is probably the best index.

On intelligence: it might very well be worth commissioning a social psychologist to devise a test for the type of intelligence required - the kind of empathetic perceptiveness that enables one to guess at people's motives for doing things, and the kind of imagination (divergent, as opposed to convergent, intelligence) required to improvise new institutional arrangements.

1 Ron Dore is a Fellow at The Institute of Development Studies. 
The right attitudes I have in mind are not so much a matter of "being keen of development", though that helps. What I have in mind is something best expressed in negative terms - lacking the automatic assumption that the way things are done in Britain, or in the industrial countries generally, is the way they ought to be done everywhere. Missionaries of cooperation, for example, have gone abroad full of enthusiasm and blind faith in the Rochdale principles only to meet total failure. It might help if every applicant for a technical assistance job was required to write an essay on "The Probable Relevance and Limitations of British Practice as a Model for Country $X$ in the Field of $Y^{\prime \prime}$ and if that essay was evaluated independently for the interview panel by two or three social scientists who have given a good deal of thought to the question of just how the development of the contemporary developing societies is likely to differ from European patterns of industrialization.

The de-emphasis on formal qualifications might help in the job of development in another way. A major obstacle to progress in many developing countries is qualificationitis. Too many jobs in African and Asian civil services filled by people whose sole claim to them lies in the fact that their parents could afford to give them 12 years of education. Countries with one doctor per 8,000 inhabitants will idiotically insist that no one should be allowed to diagnose a fever and administer penicillin unless he has had six years of medical school training. The emphasis on pre-career qualification, as opposed to youthful job performance as the criterion of occupational selection is a product of the advanced bureaucratic stage of industrialization which we have reached. It has been exported to the developing countries, inappropriately before industrialization has hardly begum. The more people we can send to these countries who are capable, though not formally qualified, and who care more about performance than about qualification, the better the chance of reversing the trend. 